\title{
Antimicrobial Activity of Chemokine CXCL10 for Dermal and Oral Microorganisms
}

\section{Grant O. Holdren ${ }^{1, \dagger}$, David J. Rosenthal ${ }^{2, \dagger}$, Jianyi Yang ${ }^{3, \dagger}$, Amber M. Bates ${ }^{2, \dagger}$, Carol L. Fischer ${ }^{2}$, Yang Zhang ${ }^{3}$, Nicole K. Brogden ${ }^{1}$ and Kim A. Brogden ${ }^{2,4, *}$}

1 Division of Pharmaceutics and Translational Therapeutics, Department of Pharmaceutical Sciences and Experimental Therapeutics, College of Pharmacy, The University of Iowa, Iowa City, IA 52242, USA; E-Mails: gholdren@gmail.com (G.O.H.); nicole-brogden@uiowa.edu (N.K.B.)

2 Dows Institute for Dental Research, College of Dentistry, The University of Iowa, Iowa City, IA 52242, USA; E-Mails: drosent@iastate.edu (D.J.R.); amber-bates@uiowa.edu (A.M.B.); carol-bratt@uiowa.edu (C.L.F.)

3 Department of Computational Medicine and Bioinformatics, The University of Michigan, 100 Washtenaw Avenue, Ann Arbor, MI 48109, USA; E-Mails: yangji@umich.edu (J.Y.); zhng@umich.edu (Y.Z.)

4 Periodontics, College of Dentistry, The University of Iowa, Iowa City, IA 52242, USA

$\dagger$ These authors contributed equally to this work.

* Author to whom correspondence should be addressed; E-Mail: kim-brogden@uiowa.edu; Tel.: +1-319-335-8077; Fax: +1-319-335-8895.

External Editor: Dr. William M. Shafer

Received: 4 September 2014; in revised form: 3 October 2014 / Accepted: 14 October 2014 / Published: 23 October 2014

\begin{abstract}
CXCL10 (IP-10) is a small $10 \mathrm{kDa}$ chemokine with antimicrobial activity. It is induced by IFN- $\gamma$, chemoattracts mononuclear cells, and promotes adhesion of $\mathrm{T}$ cells. Recently, we detected CXCL10 on the surface of the skin and in the oral cavity. In the current study, we used broth microdilution and radial diffusion assays to show that CXCL10 inhibits the growth of Escherichia coli, Staphylococcus aureus, Corynebacterium jeikeium, Corynebacterium striatum, and Candida albicans HMV4C, but not Corynebacterium bovis, Streptococcus mutans, Streptococcus mitis, Streptococcus sanguinis, Fusobacterium nucleatum, Aggregatibacter actinomycetemcomitans, Poryphromonas gingivalis, or C. albicans ATCC 64124. The reason for the selective antimicrobial activity is not yet known. However, antimicrobial activity of CXCL10 may be related to its composition and structure, as a
\end{abstract}


cationic 98 amino acid residue molecule with 10 lysine residues, 7 arginine residues, a total net charge of +11 , and a theoretical $\mathrm{pI}$ of 9.93. Modeling studies revealed that CXCL10 contains an $\alpha$-helix at the $\mathrm{N}$-terminal, three anti-parallel $\beta$-strands in the middle, and an $\alpha$-helix at the C-terminal. Thus, CXCL10, when produced on the surface of the skin or in the oral cavity, likely has antimicrobial activity and may enhance innate antimicrobial and cellular responses to the presence of select commensal or opportunistic microorganisms.

Keywords: antimicrobial; CXCL10; IP-10; dermal microorganisms; oral microorganisms; SMAP28

\section{Introduction}

CXCL10 (IP-10) is a small $10 \mathrm{kDa}$ chemokine. Structurally, it falls into the CXC family of chemokines, which differs from the $\mathrm{C}, \mathrm{CC}$, and $\mathrm{CX} 3 \mathrm{C}$ families based on variations in the separation of $\mathrm{N}$-terminal cysteines $[1,2]$. CXCL10 is induced by IFN- $\gamma$ and produced by monocytes, fibroblasts, and endothelial cells [3], as well as activated neutrophils and eosinophils [4]. Under inflammatory situations, CXCL10 chemoattracts monocytes, macrophages, natural killer cells, dendritic cells, and cytotoxic and helper T cells (specifically Th1) [5,6] and promotes adhesion of T cells. CXCL10 is expressed in higher levels with multiple disease states, including cancer [5], infectious diseases [7], psoriasis [8], and various autoimmune diseases $[9,10]$. Along with the chemoattractant activity in immune responses, CXC chemokines are active in the regulation of angiogenesis. CXCL10 is missing the ELR (Glu-Leu-Arg) motif, indicating that it acts as an inhibitor of angiogenesis [11]. Additionally, members of the CXC chemokine family function as antimicrobial peptides, serving to enhance innate antimicrobial defense [2,12]. CXCL10 has antimicrobial activity against Escherichia coli [2,12], Staphylococcus aureus [2], Listeria monocytogenes [12], Streptococcus pyogenes [13], Bacillus anthracis [14,15], and Candida albicans [2].

Recently, we and others have detected CXCL10 in and on the surface of the skin $[8,10]$ and in the oral cavity $[16,17]$. These findings suggest that CXCL10 may enhance the antimicrobial barriers in these areas. To test this, we assessed the antimicrobial activity of CXCL10 for microorganisms commonly found as commensals or pathogens on the skin and in the oral cavity.

\section{Results}

\subsection{Activity of CXCL10 on Microorganisms Commonly Found on the Skin}

CXCL10 had antimicrobial activity against select microorganisms that commonly inhabit the skin (Tables 1 and 2). However, the activity of CXCL10 was also sensitive to the conditions of the antimicrobial assays, particularly the saline and media composition of the diluent used for each microorganism in the assay. SMAP28 was used as a control peptide and inhibited the growth of these microorganisms. 
Table 1. Broth microdilution assays showing the minimal inhibitory concentration (MIC) and the minimal bactericidal concentration (MBC) of CXCL10 for microorganisms commonly found as commensals or pathogens on the skin.

\begin{tabular}{ccccc}
\hline Microorganism & $\begin{array}{c}\text { CXCL10 } \boldsymbol{\mu g} / \mathbf{m L} \text { MIC } \\
\text { (Standard Error) }\end{array}$ & $\begin{array}{c}\text { CXCL10 } \boldsymbol{\mu g} / \mathbf{m L} \text { MBC } \\
\text { (Standard Error) }\end{array}$ & $\begin{array}{c}\text { SMAP28 } \boldsymbol{\mu g} / \mathbf{m L} \text { MIC } \\
\text { (Standard Error) }\end{array}$ & $\begin{array}{c}\text { SMAP28 } \boldsymbol{\mu g} / \mathbf{m L} \text { MBC } \\
\text { (Standard Error) }\end{array}$ \\
\hline S. aureus & $>50.00$ & $>50.00$ & $4.17(1.04)$ & $6.25(0.00)$ \\
E. coli & $>50.00$ & $>50.00$ & $3.13(0.00)$ & $3.13(0.00)$ \\
C. bovis & $>50.00$ & $>50.00$ & $6.25(0.00)$ & $6.25(0.00)$ \\
C. striatum & $5.21(1.04)$ & $25.00(0.00)$ & $0.07(0.01)$ & $0.07(0.01)$ \\
C. jeikeium & $>50.00$ & $>50.00$ & $0.31(0.00)$ & $0.31(0.00)$ \\
\hline
\end{tabular}

Minimal inhibitory concentration (MIC) and minimal bactericidal concentration (MBC) assays were performed in triplicate for each microorganism. S. aureus and E. coli were cultivated in Mueller Hinton Broth (MHB) at $37{ }^{\circ} \mathrm{C}$ for $24 \mathrm{~h}$ and C. bovis, C. striatum, and C. jeikeium were cultivated in Brain Heart Infusion Broth containing $0.1 \%$ Tween 80 at $37{ }^{\circ} \mathrm{C}(\mathrm{BHI}-\mathrm{T} 80)$ for $48 \mathrm{~h}$.

Table 2. Radial diffusion assays showing the minimal inhibitory concentration (MIC) of CXCL10 for microorganisms commonly found as commensals or pathogens on the skin.

\begin{tabular}{ccc}
\hline Microorganism & $\begin{array}{c}\text { CXCL10 } \boldsymbol{\mu g} / \mathbf{m L} \text { MIC } \\
\text { (Standard Error) }\end{array}$ & $\begin{array}{c}\text { SMAP28 } \boldsymbol{\mu g} / \mathbf{m L} \text { MIC } \\
\text { (Standard Error) }\end{array}$ \\
\hline S. aureus & $125.89(0.00)$ & $10.49(1.66)$ \\
E. coli & $11.62(4.23)$ & $3.69(0.75)$ \\
C. bovis & $>200.00$ & $17.24(0.43)$ \\
C. striatum & $3.42(1.55)$ & $8.00(1.62)$ \\
C. jeikeium & $21.52(0.23)$ & $4.44(0.26)$ \\
\hline
\end{tabular}

Minimal inhibitory concentration (MIC) assays were performed in triplicate for each microorganism. S. aureus and E. coli were cultivated in Mueller Hinton Broth (MHB) at $37{ }^{\circ} \mathrm{C}$ for $24 \mathrm{~h}$; and C. bovis, C. striatum, and C. jeikeium were cultivated in Brain Heart Infusion Broth containing $0.1 \%$ Tween 80 at $37^{\circ} \mathrm{C}$ (BHI-T80) for $48 \mathrm{~h}$.

S. aureus was resistant to CXCL10 in the broth microdilution assay (MIC, MBC $>50.00 \mu \mathrm{g} / \mathrm{mL}$; Table 1) and the viable plate count assay (MIC $>100.00 \mu \mathrm{g} / \mathrm{mL}$ ) [18], but susceptible to CXCL10 in the radial diffusion assay (MIC $125.89 \mu \mathrm{g} / \mathrm{mL}$; Table 2). E. coli was resistant to CXCL10 in the broth microdilution assay (MIC, MBC $>50.00 \mu \mathrm{g} / \mathrm{mL}$; Table 1), but susceptible to CXCL10 in viable plate count assay (MIC $<100.00 \mu \mathrm{g} / \mathrm{mL}$ ) [19] and in the radial diffusion assay (MIC $3.13 \mu \mathrm{g} / \mathrm{mL}$ ). C. bovis was resistant to CXCL10 in the broth microdilution assay (MIC, MBC $>50.00 \mu \mathrm{g} / \mathrm{mL}$; Table 1); the viable plate count assay ( $\mathrm{MIC}>100.00 \mu \mathrm{g} / \mathrm{mL}$ ) [20], and the radial diffusion assay (MIC $>200.00 \mu \mathrm{g} / \mathrm{mL}$; Table 2). C. jeikeium was resistant to CXCL10 (MIC, MBC $>50.00 \mu \mathrm{g} / \mathrm{mL}$ ) in the broth microdilution and radial diffusion assays. In contrast, $C$. striatum was sensitive to CXCL10 in the broth microdilution (MIC, $5.21 \mu \mathrm{g} / \mathrm{mL}$; MBC $25.00 \mu \mathrm{g} / \mathrm{mL}$ ) and radial diffusion (MIC, $19.59 \mu \mathrm{g} / \mathrm{mL}$ ) assays. 


\subsection{Activity of CXCL10 on Microorganisms Commonly Found in the Oral Cavity}

CXCL10 did not have antimicrobial activity against bacteria that commonly inhabit the oral cavity (Table 3). In radial diffusion assays, CXCL10 did not inhibit the growth Streptococcus mutans, Streptococcus mitis, Streptococcus sanguinis, Fusobacterium nucleatum, Aggregatibacter actinomycetemcomitans, or Poryphromonas gingivalis. Again, SMAP28 was used as a control peptide and inhibited the growth of these microorganisms.

Table 3. Radial diffusion assays showing the minimal inhibitory concentration (MIC) of CXCL10 for microorganisms commonly found as commensals or pathogens in the oral cavity.

\begin{tabular}{lcc}
\hline \multicolumn{1}{c}{ Microorganism } & $\begin{array}{c}\text { CXCL10 } \boldsymbol{\mu g} / \mathbf{m L} \text { MIC } \\
\text { (Standard Error) }\end{array}$ & $\begin{array}{c}\text { SMAP28 } \boldsymbol{\mu g} / \mathbf{m L} \text { MIC } \\
\text { (Standard Error) }\end{array}$ \\
\hline S. mutans & $>200.00$ & $40.51(2.70)$ \\
S. mitis & $>200.00$ & $125.89(0.00)$ \\
S. sanguinis & $>200.00$ & $61.55(2.80)$ \\
F. nucleatum & $>1000.00$ & $39.47(5.62)$ \\
P. gingivalis 381 & $>1000.00$ & $69.70(22.74)$ \\
P. gingivalis ATCC 33277 & $>1000.00$ & $74.42(11.32)$ \\
A. actinomycetemcomitans & $>1000.00$ & $26.18(3.81)$ \\
\hline
\end{tabular}

Assays were performed in triplicate for each microorganism. S. mutans, S. mitis, and S. sanguinis were cultivated in trypticase soy broth with yeast extract (TSBYE) at $37{ }^{\circ} \mathrm{C} ; \mathrm{F}$. nucleatum was cultivated in Schaedler's broth at $37{ }^{\circ} \mathrm{C}$ in an anaerobic environment; $P$. gingivalis was cultured in Tryptic Soy Broth supplemented with vitamin $\mathrm{K} 1$ and hemin at $37^{\circ} \mathrm{C}$ in an anaerobic environment; and A. actinomycetemcomitans was cultivated in TSBYE at $37{ }^{\circ} \mathrm{C}$ in $5.0 \% \mathrm{CO}_{2}$.

\subsection{Activity of CXCL10 on C. albicans Commonly Found on the Skin and in the Oral Cavity}

C. albicans ATCC 64124 was resistant to CXCL10 in the broth microdilution (MIC, MBC $>50.0 \mu \mathrm{g} / \mathrm{mL}$ ) and radial diffusion (MIC $>50.0 \mu \mathrm{g} / \mathrm{mL}$ ) assays (Table 4). In contrast, C. albicans HMV4C was resistant to CXCL10 in the broth microdilution assay (MIC, MBC $>50.0 \mu \mathrm{g} / \mathrm{mL}$ ), yet susceptible to CXCL10 in the radial diffusion assay (MIC $23.90 \mu \mathrm{g} / \mathrm{mL}$ ).

Table 4. Broth microdilution and radial diffusion assays showing the minimal inhibitory concentration (MIC) and the minimal bactericidal concentration (MBC) of CXCL10 for C. albicans commonly found as a commensal or pathogen on the skin and in the oral cavity.

\begin{tabular}{lcccc}
\hline \multicolumn{1}{c}{ Microorganism } & $\begin{array}{c}\text { CXCL10 } \boldsymbol{\mu g} / \mathbf{m L} \text { MIC } \\
\text { (Standard Error) }\end{array}$ & $\begin{array}{c}\text { CXCL10 } \boldsymbol{\mu g} / \mathbf{m L} \text { MBC } \\
\text { (Standard Error) }\end{array}$ & $\begin{array}{c}\text { SMAP28 } \boldsymbol{\mu g} / \mathbf{m L} \text { MIC } \\
\text { (Standard Error) }\end{array}$ & $\begin{array}{c}\text { SMAP28 } \boldsymbol{\mu g} / \mathbf{m L} \text { MBC } \\
\text { (Standard Error) }\end{array}$ \\
\hline $\begin{array}{l}\text { Broth microdilution assay } \\
\text { C. albicans ATCC 64124 }\end{array}$ & $>50.00$ & $>50.00$ & $12.50(0.00)$ & $12.50(0.00)$ \\
C. albicans HMV4C & $>50.00$ & $>50.00$ & $12.50(0.00)$ & $16.67(4.17)$ \\
Radial diffusion assay & & & & $\mathrm{n} / \mathrm{a}$ \\
C. albicans ATCC 64124 & $>1,000.00$ & $\mathrm{n} / \mathrm{a}$ & $39.73(18.60)$ & $\mathrm{n} / \mathrm{a}$ \\
C. albicans HMV4C & $23.90(10.38)$ & $\mathrm{n} / \mathrm{a}$ & $18.90(2.13)$ & \\
\hline
\end{tabular}

Minimal inhibitory concentration (MIC) assays were performed in triplicate for each strain. C. albicans ATCC 64124 and C. albicans HMV4C were grown on trypticase soy agar (TSA) overnight and then cultivated in RPMI 1640 at $37^{\circ} \mathrm{C}$ for $3 \mathrm{~h}$. $\mathrm{n} / \mathrm{a}=$ not applicable. 


\subsection{Proposed Structure of CXCL10}

The structure model of the protein CXCL10 was predicted by I-TASSER [21], and is shown in Figure 1A. The top templates used by I-TASSER include: 1080A and 1lv9A. A confidence score (C-score) was used to estimate the accuracy of the I-TASSER model. This score is based on the clustering structural density/consensus significance of multiple threading templates. In the present study, the model was very accurate with a $\mathrm{C}$-score of -0.47 , estimated $\mathrm{TM}$-score $=0.65 \pm 0.13$, and estimated $\mathrm{RMSD}=4.8 \pm 3.1 \AA$. Shown in Figure 1B is the local accuracy estimation. The residues between 29 and 93 have higher resolution (with predicted distance to native below $4 \AA$ ), which correspond to three antiparallel $\beta$-strands in the middle and an $\alpha$-helix at the C-terminal.

Figure 1. The structure modeling results of CXCL10. (A) I-TASSER model; (B) Estimated local accuracy.

(A)

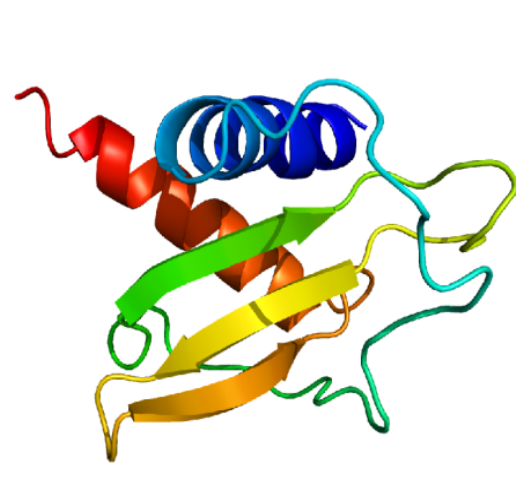

(B)

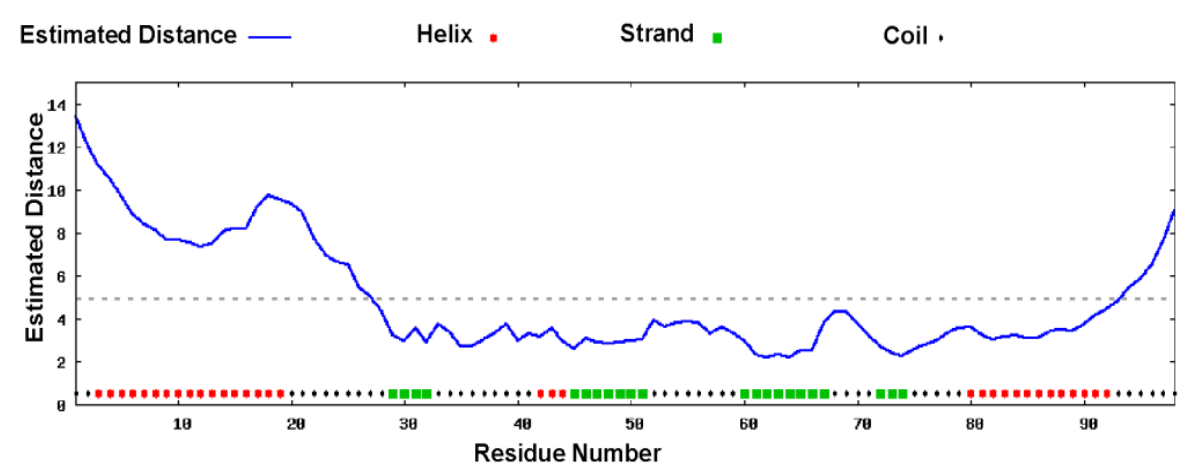

\section{Discussion}

In the current study, we found that CXCL10 has selective antimicrobial activity. In broth microdilution and radial diffusion assays, CXCL10 inhibits the growth of E. coli, S. aureus, C. jeikeium, C. striatum, and C. albicans HMV4C, but not C. bovis, S. mutans, S. mitis, S. sanguinis, F. nucleatum, A. actinomycetemcomitans, $P$. gingivalis strain 381 and ATCC 33277, or C. albicans ATCC 64124 (Tables 1-4). Antimicrobial activity of CXCL10 may be related to its strong cationic composition and unique structure of three anti-parallel $\beta$-strands in the middle and an $\alpha$-helix at the C-terminal. Thus CXCL10, when produced on the surface of the skin and in the oral cavity, may enhance innate antimicrobial and cellular responses to the presence of select microorganisms.

The skin and oral cavity are continually exposed to high concentrations of commensal and environmental microorganisms and both of these sites produce a vast diversity of antimicrobial substances as part of their innate immune host defense. This includes antimicrobial peptides, antimicrobial proteins, enzymes, and antimicrobial lipids. For example, the skin produces over 13 different antimicrobial substances [22]; the gingival crevicular fluid contains over 24 antimicrobial substances [23-25]; and saliva contains over 45 antimicrobial substances [23-25].

Cole and colleagues asked whether antimicrobial concentrations of CXCL10 could be achieved in vivo [12]. Based on the amount of CXCL10 produced from IFN- $\gamma$ stimulated peripheral blood mononuclear cells and the density of mononuclear cells in lesions, they hypothesized that CXCL10 could 
be produced in areas of chronic inflammation in $\mu \mathrm{g} / \mathrm{mL}$ amounts. Furthermore they propose that CXCL10 concentrations in vivo in plasma of individuals with meliodosis can also reach the MIC concentrations they observed in their study. We and others have recently detected CXCL10 on the surface of the skin and in the oral cavity. In a study of 23 subjects, surface skin wash fluid contained 0.0 to $59.3 \mathrm{pg} / \mathrm{mL}$ of CXCL10 (unpublished findings [26]); in a study of 20 subjects, saliva contained $634.0 \pm 158.9 \mathrm{pg} / \mathrm{mL}$ CXCL10 [27]; in a study of 52 subjects, gingival crevicular fluid contained 36.0 to $3672.0 \mathrm{pg} / \mathrm{mL}$ CXCL10 [16]; and in a study of 6 subjects, gingival crevicular fluid contained 48.7 to $29,280.0 \mathrm{pg} / \mathrm{mL}$ CXCL10 [17]. These sites also have an incredible abundance and diversity of commensal and opportunistic microflora [28-32]. The presence of CXCL10 at these sites suggests that it may contribute to innate host defense.

CXCL10 has been reported to have antimicrobial activity against E. coli [2,12], S. aureus [2], L. monocytogenes [12], S. pyogenes [13], B. anthracis [14,15], and C. albicans [2]. In this study we extend these findings and report that CXCL10 has selective antimicrobial activity against microorganisms found on the skin and in the oral cavity, thus contributing to antimicrobial host defense by other antimicrobial peptides, antimicrobial proteins, enzymes, and antimicrobial lipids in these areas. Among microorganisms commonly found on the skin, S. aureus and C. bovis were more resistant to CXCL10 and E. coli, C. jeikeium, and C. striatum were more susceptible to CXCL10. Antimicrobial activity was likely dependent upon the saline and media composition of the diluents used in these assays. This was not an unexpected finding. Cole and colleagues nicely showed that the antimicrobial activity of CXCL10 for E. coli was dependent upon the saline concentration of the media [12]. E. coli was very susceptible to CXCL10 in $10 \mathrm{mM}$ sodium phosphate buffer, $\mathrm{pH} 7.4$ (MIC, $4.4 \mu \mathrm{g} / \mathrm{mL}$ ); moderately susceptible in phosphate buffer with $50 \mathrm{mM} \mathrm{NaCl}$ (MIC, 25.0-50.0 $\mu \mathrm{g} / \mathrm{mL}$ ); and more resistant in phosphate buffer with $100 \mathrm{mM} \mathrm{NaCl}$ (MIC $>50.0 \mu \mathrm{g} / \mathrm{mL}$ ). Similarly, the antimicrobial activity of CXCL10 for $S$. pyogenes was diminished in the presence of $150 \mathrm{mM} \mathrm{NaCl}$ [13].

The effect of saline and media composition of the diluent impacts the outcomes of the assays and it would be reasonable to assume that in vivo, antimicrobial activity of CXCL10 would be greater in microenvironments with higher concentrations of CXCL10 and lower amounts of saline and protein from serous fluid or plasma.

Yang and colleagues found that $S$. aureus was susceptible to CXCL10 [2]. In the current study, we found that $S$. aureus was resistant to CXCL10 in broth microdilution assays (MIC, MBC $>50.00 \mu \mathrm{g} / \mathrm{mL}$; Table 1) yet susceptible to CXCL10 in radial diffusion assays (MIC $125.89 \mu \mathrm{g} / \mathrm{mL}$; Table 2). The reason for this difference is not known but again may be related to the saline and media composition of the diluents used in the broth microdilution assay or may be related to differences among strains. Differences among strains do occur. For example, Yang and colleagues found that C. albicans was susceptible to CXCL10 [2]. We found that C. albicans ATCC 64124 was resistant to CXCL10 (MIC $>50.0 \mu \mathrm{g} / \mathrm{mL}$ in the broth microdilution assay; Table 4); C. albicans HMV4C was resistant to CXCL10 (MIC > 50.0 $\mu \mathrm{g} / \mathrm{mL}$ in the broth microdilution assay; Table 4), yet C. albicans HMV4C was susceptible to CXCL10 (MIC $23.90 \mu \mathrm{g} / \mathrm{mL}$ in the radial diffusion assay; Table 4).

Interestingly, bacteria commonly found in the oral cavity were resistant to CXCL10. C. albicans, an opportunistic pathogen on the skin and in the oral cavity, was resistant or susceptible to CXCL10, depending upon the strain. Differences among strains do occur and this would warrant using a number of strains of each species in subsequent work. 
The exact mechanism for the antimicrobial activity of CXCL10 for bacteria is not yet known but is likely related to its unique composition and structure. CXCL10 contains 10 lysine residues, 7 arginine residues, has a net charge of +11 , and has a theoretical pI of 9.93. This likely facilitates the physical attraction of CXCL10 for the negatively charged microbial surface [12] and activity is influenced by the composition of components in the surrounding environment. Antimicrobial activity of CXCL10 is known to decrease in complex microbiological media and antimicrobial activity rapidly decreases as the concentration of $\mathrm{NaCl}$ increases in assay diluents [12,13]. What happens next is not well known. CXCL10 may possibly interact and form pores in the microbial cytoplasmic membrane. Alternately, CXCL10 may target specific cytoplasmic membrane proteins. One proposed target is FtsX, an integral cytoplasmic inner membrane protein thought to form the substrate translocation channel of a putative ABC transporter [14]. In cells treated with CXCL10 and processed for immunoelectron microscopy, CXCL10 bound to the bacterial cell membrane and was associated with loss of cellular integrity [14].

We wanted to compare the modeled structure of CXCL10 with the structure of CXCL9. Egesten and colleagues assessed the structure of chemokine CXCL9 (MIG) with antimicrobial activity [13]. The Nterminus of CXCL9 contained a region composed of 3 antiparallel $\beta$-strands and the C-terminus contained a region composed of an $\alpha$-helix. When areas of this molecule were synthesized and tested against $S$. pyogenes, the N-terminus did not have antimicrobial activity but the C-terminus did [13]. Yang and colleagues assessed the structure of CXCL10 [2]. CXCL10 had a secondary structure with a number of uniquely rich segments. It is rich in positively charged amino acid residues and has a uniquely positive charged C-terminus. In the current study, we found that the global topology of CXCL10 was similar to that of CXCL9 (Figure 1A): the middle of CXCL10 contained a region composed of 3 antiparallel $\beta$-strands and the $\mathrm{C}$-terminus contained a region composed of an $\alpha$-helix (Figures 1A). The major difference is that our model contains one $\alpha$-helix at the $\mathrm{N}$-terminus (Figure 1A). When further modeled, it would appear that the C-terminus $\alpha$-helix would be expected to bind to other proteins and thus may be involved in antimicrobial activity similar to that proposed for CXCL9 (Figure 2).

\section{Experimental Section}

\subsection{Microorganisms and Culture Conditions}

Representative microorganisms commonly found on the skin surface were used and cultivated as previously described [33]. S. aureus ATCC 29213 was cultivated in Mueller Hinton Broth (MHB) at $37^{\circ} \mathrm{C}$ for $24 \mathrm{~h}$; E. coli ATCC 12795 was cultivated in MHB at $37{ }^{\circ} \mathrm{C}$ for $24 \mathrm{~h}$; and C. bovis ATCC 7715, C. jeikeium ATCC 43734, and C. striatum ATCC 7094 were cultivated in Brain Heart Infusion Broth containing $0.1 \%$ Tween 80 (BHIB-T80) at $37^{\circ} \mathrm{C}$ for $48 \mathrm{~h}$.

Representative microorganisms commonly found in the oral cavity were also used and cultivated as previously described [33,34]. S. mutans ATCC 25175, S. mitis ATCC 49456, and S. sanguinis ATCC 10556 were cultivated in trypticase soy broth with $0.6 \%$ yeast extract (TSBYE) at $37{ }^{\circ} \mathrm{C}$; F. nucleatum ATCC 25586 was cultivated in Schaedler's broth at $37{ }^{\circ} \mathrm{C}$ in an anaerobic environment; P. gingivalis strain 381 and P. gingivalis ATCC 33277 were cultured in Tryptic Soy Broth (TSB; Difco Laboratories, Detroit, MI, USA) supplemented with vitamin K1 and hemin (Sigma Chemical Co., 
St Louis, MO, USA) at $37^{\circ} \mathrm{C}$ in an anaerobic environment; and A. actinomycetemcomitans ATCC 43718 was cultivated in TSBYE at $37^{\circ} \mathrm{C}$ in $5.0 \% \mathrm{CO}_{2}$.

C. albicans ATCC 64124 and C. albicans HMV4C were grown on trypticase soy agar (TSA) and cultivated in RPMI 1640 at $37^{\circ} \mathrm{C}$ for $3 \mathrm{~h}$. Their identities were confirmed with a Bruker Daltonik MALDI Biotyper (State Hygienic Laboratory, University of Iowa Research Park, Coralville, IA, USA).

Prior to the antimicrobial assays, all cultures were transferred to fresh medium and incubated for $3 \mathrm{~h}$ in their respective culture conditions. Cultures were then adjusted to contain $\sim 1.0 \times 10^{8} \mathrm{cfu} / \mathrm{mL}$ (optical density 0.108; $600 \mathrm{~nm}$; Spectronic 20D1, Thermo Fisher Scientific, Inc., Waltham, MA, USA) and then diluted to $10^{-2}$ to $10^{-3}$-fold in fresh media (depending upon the specific microorganism).

\subsection{Chemokine and Antimicrobial Peptide}

Recombinant CXCL10 (Peprotech, Rocky Hill, NJ, USA) was used. CXCL10 was suspended in $0.01 \%$ acetic acid to a concentration of $1000.0 \mu \mathrm{g} / \mathrm{mL}$, gently mixed, dispensed as $100 \mu \mathrm{L}$ aliquots into cryotubes, and frozen until use.

Sheep myeloid antimicrobial peptide (SMAP) 28 (NeoMPS, Inc., San Diego, CA, USA) was used as a positive control peptide [35] with antimicrobial activity against many of the microorganisms used in this study [36]. SAMP28 is robust and antimicrobial activity is not affected in vitro [37] or in vivo [38] by the presence of complex microbiological media and increased concentrations of $\mathrm{NaCl}$. SMAP28 was suspended in $0.01 \%$ acetic acid to a concentration of $1000.0 \mu \mathrm{g} / \mathrm{mL}$, gently mixed, dispensed as $100 \mu \mathrm{L}$ aliquots into cryotubes, and frozen until use.

\subsection{Broth Microdilution Assay}

A broth microdilution assay was used to determine the antimicrobial activities of CXCL10 and SMAP28 for bacteria [35] and a modified broth microdilution assay was used to determine the antimicrobial activities of CXCL10 and SMAP28 for C. albicans [39]. Briefly, 0.01\% acetic acid was added to the wells of column 1 to 12 of microtiter plates (Immulon 1 plates, ISC Bioexpress, Kaysville, UT, USA). $100 \mu \mathrm{L}$ of CXCL10 or SMAP28 was then added to the wells in column 1 and diluted 2-fold from column 1 to column 10 using a multi-channel pipetter. $100 \mu \mathrm{L}$ of bacterial culture was added to each well from column 1 to column 11. Column 11 served as the positive growth control (in diluent). $100 \mu \mathrm{L}$ of sterile culture media was added to the wells in column 12 and used as the sterility controls and plate blanks. Alternately, $100 \mu \mathrm{L}$ of a $3 \mathrm{~h} \mathrm{C}$. albicans culture in RPMI with resazurin (Alamar Blue, Invitrogen Corp., Carlsbad, CA, USA) was added to each well from column 1 to column 11. Column 11 served as the positive growth control (in diluent). $100 \mu \mathrm{L}$ of sterile RPMI with resazurin was added to the wells in column 12 and used as the sterility controls and plate blanks. After set up, the plates were incubated overnight at $37^{\circ} \mathrm{C}$ in the appropriate culture conditions. The microbial growth in the presence of CXCL10 or SMAP28 was assessed at $600 \mathrm{~nm}$ in the spectrophotometer (PowerWaveX, Bio-Tek instruments, Inc., Winooski, VT, USA). C. albicans growth in the presence of CXCL10 or SMAP28 was assessed by measuring the metabolic reduction of resazurin to resorufin using an excitation wavelength of $544 \mathrm{~nm}$ and an emission wavelength of $590 \mathrm{~nm}$ (SpectraMax M2e Multi-Mode Microplate Reader, Molecular Devices, LLC, Sunnyvale, CA, USA). 
The minimal inhibitory concentration (MIC) was determined to be the lowest concentration of peptides that inhibited microbial growth by more than $50 \%$ of the positive growth control in each row. The wells were cultured onto the respective agars and the minimal bactericidal concentration (MBC) was determined to be the lowest concentration of peptides that inhibited microbial growth on agar. Broth microdilution assays were performed in triplicate for each microorganism.

\subsection{Radial Diffusion Assay}

A radial diffusion assay was used to determine the antimicrobial activities of CXCL10 and SMAP28 for $S$. aureus, E. coli, C. bovis, C. jeikeium, and C. striatum [12] and a modified radial diffusion assay was used to determine the antimicrobial activities of CXCL10 and SMAP28 for S. mutans, S. mitis, S. sanguinis, F. nucleatum, A. actinomycetemcomitans, and P. gingivalis [36]. Briefly, $4.0 \times 10^{6}$ microorganisms were suspended in $25.0 \mathrm{~mL}$ of $1 \%$ agarose in 0.01 sodium phosphate buffer, $\mathrm{pH} 7.4$ at $50{ }^{\circ} \mathrm{C}$ and pipetted into square Petri dishes. When solidified, $2.0 \mathrm{~mm}$ diameter wells were punched into the agar. Five microliters of CXCL10 or SMAP28 at 1000.0, 500.0, 250.0, 125.0, 62.5, and $0.0 \mu \mathrm{g} / \mathrm{mL}$ were added per well. The plates were incubated at $37^{\circ} \mathrm{C}$. After $3 \mathrm{~h}, 10.0 \mathrm{~mL}$ of $1.0 \%$ agarose containing $6.0 \%$ of the respective microbial media was added and allowed to solidify. The plates were incubated at $37^{\circ} \mathrm{C}$ in their respective culture conditions. At $18 \mathrm{~h}$, clear zones representing microbial growth inhibition were measured. Radial diffusion units were calculated as the diameter of the clear zone less the $2.0 \mathrm{~mm}$ diameter of the well $\times 10$. The radial diffusion units were plotted against the $\log _{10}$ of the peptide concentration and the MIC was determined to be anti-log 10 of the $x$-intercept. The radial diffusion assays were performed in triplicate for each microorganism.

\subsection{Viable Plate Count Assay}

A viable plate count assay was used to assess the direct effects of CXCL10 on the viability of dermal and oral microorganisms. For this, microorganisms were cultivated as described above, adjusted to contain $\sim 1.0 \times 10^{8} \mathrm{cfu} / \mathrm{mL}$ (optical density 0.108; $600 \mathrm{~nm}$; Spectronic 20D1, Thermo Fisher Scientific, Inc., Waltham, MA, USA), and then diluted $10^{-4}$-fold in sterile water. $50 \mu \mathrm{L}$ containing $\sim 500 \mathrm{cfu}$, was added to $50 \mu \mathrm{L}$ of CXCL10 in $0.01 \%$ acetic acid, SMAP28 in $0.01 \%$ acetic acid, or $0.01 \%$ acetic acid. After incubation for one hour at $37{ }^{\circ} \mathrm{C}, 25 \mu \mathrm{L}$ was removed and spotted in triplicate on the respective agar for each microorganism. After incubation for $24 \mathrm{~h}$, colonies were counted.

\subsection{Modeling the Structure of CXCL10}

The structure of CXCL10 was predicted using the iterative threading assembly refinement (I-TASSER) server $[21,40]$. Briefly, the 98 amino acid residue FASTA format sequence of CXCL10 was threaded against the PDB library using the meta-threading algorithm LOMETS to identify homologues templates. Fragments that were excised from the threading templates were then reassembled into full-length models by replica exchange Monte Carlo simulations with the threading unaligned regions (mainly loops) built by ab initio folding. The lowest free-energy conformation was selected by clustering the Monte Carlo simulation structures using SPICKER39. Next, fragment assembly simulation was performed again starting from the SPICKER cluster centroids, where the spatial restraints collected from both the 
LOMETS templates and the analogy PDB structures by TM-align were used to guide the reassembly simulations. Finally, the models were refined in the atomic-level by the fragment guided molecular dynamics (FG-MD) simulations.

To examine the biological function of the CXCL10 sequence, the COACH algorithm [41] was used to match the I-TASSER model to the protein function library BioLiP [42]. As shown in Figure 2, the CXCL10 was predicted to interact with a peptide (18 residues from the extracellular portion of the receptor CXCR-1) using the template interleukin-8 (PDB ID: 1ilpA).

Figure 2. The CXCL10 (in green cartoon) is predicted to interact with a peptide (in red spheres).

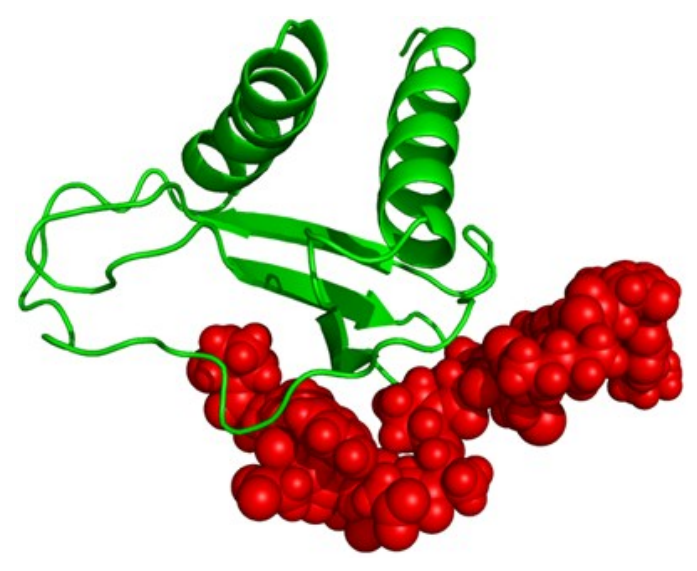

\section{Conclusions}

CXCL10, when produced on the surface of the skin and in the oral cavity, may have a broader role than previously thought in enhancing innate antimicrobial and cellular responses to the presence of microorganisms. In this study we show that CXCL10 has antimicrobial activity against select microorganisms commonly found on the skin or in the oral cavity. Antimicrobial activity may be due to the unique characteristics of CXCL10.

\section{Acknowledgments}

This work was supported by NIH NIDCR grant R01 DE014390. The authors thank Ryan T. Jepson, Clinical Lab Technical Specialist, State Hygienic Laboratory, University of Iowa Research Park, Coralville, IA for his help in confirming the identity of the Candida albicans cultures.

\section{Author Contributions}

In this study, we assessed the ability of CXCL10 to have antimicrobial activity against microorganisms commonly found on the skin (Grant O. Holdren and Amber M. Bates) and in the oral cavity (David J. Rosenthal, Amber M. Bates and Carol L. Fischer) using broth microdilution assays (Grant O. Holdren, David J. Rosenthal and Amber M. Bates) and radial diffusion assays (Grant O. Holdren, David J. Rosenthal, Amber M. Bates and Carol L. Fischer). The proposed structure of CXCL10 was determined at the Department of Computational Medicine \& Bioinformatics, The University of Michigan (Jianyi Yang and Yang Zhang). Nicole K. Brogden and Kim A. Brogden conceived the study and Nicole K. Brogden, Carol L. Fischer and Kim A. Brogden wrote the main manuscript. 


\section{Conflicts of Interest}

The authors declare no conflict of interest.

\section{References}

1. Zlotnik, A.; Yoshie, O. Chemokines: A new classification system and their role in immunity. Immunity 2000, 12, 121-127.

2. Yang, D.; Chen, Q.; Hoover, D.M.; Staley, P.; Tucker, K.D.; Lubkowski, J.; Oppenheim, J.J. Many chemokines including CCL20/MIP-3alpha display antimicrobial activity. J. Leukoc. Biol. 2003, 74, $448-455$.

3. Luster, A.D.; Unkeless, J.C.; Ravetch, J.V. Gamma-interferon transcriptionally regulates an early-response gene containing homology to platelet proteins. Nature 1985, 315, 672-676.

4. Dyer, K.D.; Percopo, C.M.; Fischer, E.R.; Gabryszewski, S.J.; Rosenberg, H.F. Pneumoviruses infect eosinophils and elicit MyD88-dependent release of chemoattractant cytokines and interleukin-6. Blood 2009, 114, 2649-2656.

5. Liu, M.; Guo, S.; Stiles, J.K. The emerging role of CXCL10 in cancer (Review). Oncol. Lett. 2011, 2, 583-589.

6. Bonecchi, R.; Bianchi, G.; Bordignon, P.P.; D’Ambrosio, D.; Lang, R.; Borsatti, A.; Sozzani, S.; Allavena, P.; Gray, P.A.; Mantovani, A.; et al. Differential expression of chemokine receptors and chemotactic responsiveness of type $1 \mathrm{~T}$ helper cells (Th1s) and Th2s. J. Exp. Med. 1998, 187, 129-134.

7. Liu, M.; Guo, S.; Hibbert, J.M.; Jain, V.; Singh, N.; Wilson, N.O.; Stiles, J.K. CXCL10/IP-10 in infectious diseases pathogenesis and potential therapeutic implications. Cytokine Growth Factor Rev. 2011, 22, 121-130.

8. Goebeler, M.; Toksoy, A.; Spandau, U.; Engelhardt, E.; Brocker, E.B.; Gillitzer, R. The C-X-C chemokine Mig is highly expressed in the papillae of psoriatic lesions. J. Pathol. 1998, 184, 89-95.

9. Lee, E.Y.; Lee, Z.H.; Song, Y.W. CXCL10 and autoimmune diseases. Autoimmun. Rev. 2009, 8, 379-383.

10. Flier, J.; Boorsma, D.M.; van Beek, P.J.; Nieboer, C.; Stoof, T.J.; Willemze, R.; Tensen, C.P. Differential expression of CXCR3 targeting chemokines CXCL10, CXCL9, and CXCL11 in different types of skin inflammation. J. Pathol. 2001, 194, 398-405.

11. Belperio, J.A.; Keane, M.P.; Arenberg, D.A.; Addison, C.L.; Ehlert, J.E.; Burdick, M.D.; Strieter, R.M. CXC chemokines in angiogenesis. J. Leukoc. Biol. 2000, 68, 1-8.

12. Cole, A.M.; Ganz, T.; Liese, A.M.; Burdick, M.D.; Liu, L.; Strieter, R.M. Cutting edge: IFN-inducible ELR-CXC chemokines display defensin-like antimicrobial activity. J. Immunol. 2001, 167, 623-627.

13. Egesten, A.; Eliasson, M.; Johansson, H.M.; Olin, A.I.; Morgelin, M.; Mueller, A.; Pease, J.E.; Frick, I.M.; Bjorck, L. The CXC chemokine MIG/CXCL9 is important in innate immunity against Streptococcus pyogenes. J. Infect. Dis. 2007, 195, 684-693. 
14. Crawford, M.A.; Lowe, D.E.; Fisher, D.J.; Stibitz, S.; Plaut, R.D.; Beaber, J.W.; Zemansky, J.; Mehrad, B.; Glomski, I.J.; Strieter, R.M.; et al. Identification of the bacterial protein FtsX as a unique target of chemokine-mediated antimicrobial activity against Bacillus anthracis. Proc. Natl. Acad. Sci. USA 2011, 108, 17159-17164.

15. Crawford, M.A.; Burdick, M.D.; Glomski, I.J.; Boyer, A.E.; Barr, J.R.; Mehrad, B.; Strieter, R.M.; Hughes, M.A. Interferon-inducible CXC chemokines directly contribute to host defense against inhalational anthrax in a murine model of infection. PLoS Pathog. 2010, 6, e1001199.

16. Tymkiw, K.D.; Thunell, D.H.; Johnson, G.K.; Joly, S.; Burnell, K.K.; Cavanaugh, J.E.; Brogden, K.A.; Guthmiller, J.M. Influence of smoking on gingival crevicular fluid cytokines in severe chronic periodontitis. J. Clin. Periodontol. 2011, 38, 219-228.

17. Thunell, D.H.; Tymkiw, K.D.; Johnson, G.K.; Joly, S.; Burnell, K.K.; Cavanaugh, J.E.; Brogden, K.A.; Guthmiller, J.M. A multiplex immunoassay demonstrates reductions in gingival crevicular fluid cytokines following initial periodontal therapy. J. Periodontal. Res. 2010, 45, 148-152.

18. Holdren, G.O.; Rosenthal, D.J.; Yang, J.; Bates, A.M.; Fischer, D.L.; Zhang, Y.; Brogden, N.K.; Brogden, K.A. Dows Institute for Dental Research, College of Dentistry, The University of Iowa, Iowa City, IA, USA. Unpublished data set 1, 2014.

19. Holdren, G.O.; Rosenthal, D.J.; Yang, J.; Bates, A.M.; Fischer, D.L.; Zhang, Y.; Brogden, N.K.; Brogden, K.A. Dows Institute for Dental Research, College of Dentistry, The University of Iowa, Iowa City, IA, USA. Unpublished data set 2, 2014.

20. Holdren, G.O.; Rosenthal, D.J.; Yang, J.; Bates, A.M.; Fischer, D.L.; Zhang, Y.; Brogden, N.K.; Brogden, K.A. Dows Institute for Dental Research, College of Dentistry, The University of Iowa, Iowa City, IA, USA. Unpublished data set 3, 2014.

21. Roy, A.; Kucukural, A.; Zhang, Y. I-TASSER: A unified platform for automated protein structure and function prediction. Nat. Protoc. 2010, 5, 725-738.

22. Brogden, N.K.; Mehalick, L.; Fischer, C.L.; Wertz, P.W.; Brogden, K.A. The emerging role of peptides and lipids as antimicrobial epidermal barriers and modulators of local inflammation. Skin Pharmacol. Physiol. 2012, 25, 167-181.

23. Gorr, S.U. Antimicrobial peptides of the oral cavity. Periodontol. 2000 2009, 51, 152-180.

24. Gorr, S.U. Antimicrobial peptides in periodontal innate defense. Front. Oral Biol. 2012, 15, 84-98.

25. Gorr, S.U.; Abdolhosseini, M. Antimicrobial peptides and periodontal disease. J. Clin. Periodontol. 2011, 38, S126-S141.

26. Holdren, G.O.; Fischer, D.L.; Brogden, K.A.; Brogden, N.K. Division of Pharmaceutics and Translational Therapeutics, Department of Pharmaceutical Sciences and Experimental Therapeutics, College of Pharmacy, The University of Iowa: Iowa City, IA, USA. Unpublished data set 4, 2014.

27. Khan, A. Detection and quantitation of forty eight cytokines, chemokines, growth factors and nine acute phase proteins in healthy human plasma, saliva and urine. J. Proteomics 2012, 75, 4802-4819.

28. Aas, J.A.; Paster, B.J.; Stokes, L.N.; Olsen, I.; Dewhirst, F.E. Defining the normal bacterial flora of the oral cavity. J. Clin. Microbiol. 2005, 43, 5721-5732.

29. Paster, B.J.; Boches, S.K.; Galvin, J.L.; Ericson, R.E.; Lau, C.N.; Levanos, V.A.; Sahasrabudhe, A.; Dewhirst, F.E. Bacterial diversity in human subgingival plaque. J. Bacteriol. 2001, 183, 3770-3783.

30. Grice, E.A.; Segre, J.A. The skin microbiome. Nat. Rev. Microbiol. 2011, 9, 244-253. 
31. Ding, T.; Schloss, P.D. Dynamics and associations of microbial community types across the human body. Nature 2014, 509, 357-360.

32. Jorth, P.; Turner, K.H.; Gumus, P.; Nizam, N.; Buduneli, N.; Whiteley, M. Metatranscriptomics of the human oral microbiome during health and disease. MBio 2014, 5, e01012-e01014.

33. Fischer, C.L.; Drake, D.R.; Dawson, D.V.; Blanchette, D.R.; Brogden, K.A.; Wertz, P.W. Antibacterial activity of sphingoid bases and fatty acids against Gram-positive and Gram-negative bacteria. Antimicrob. Agents Chemother. 2012, 56, 1157-1161.

34. Fischer, C.L.; Walters, K.S.; Drake, D.R.; Dawson, D.V.; Blanchette, D.R.; Brogden, K.A.; Wertz, P.W. Oral mucosal lipids are antibacterial against Porphyromonas gingivalis, induce ultrastructural damage, and alter bacterial lipid and protein compositions. Int. J. Oral. Sci. 2013, 5, 130-140.

35. Brogden, K.A.; Nordholm, G.; Ackermann, M. Antimicrobial activity of cathelicidins BMAP28, SMAP28, SMAP29, and PMAP23 against Pasteurella multocida is more broad-spectrum than host species specific. Vet. Microbiol. 2007, 119, 76-81.

36. Joly, S.; Maze, C.; McCray, P.B., Jr.; Guthmiller, J.M. Human beta-defensins 2 and 3 demonstrate strain-selective activity against oral microorganisms. J. Clin. Microbiol. 2004, 42, 1024-1029.

37. Brogden, N.K.; Brogden, K.A. Will new generations of modified antimicrobial peptides improve their potential as pharmaceuticals? Int. J. Antimicrob. Agents 2011, 38, 217-225.

38. Brogden, K.A.; Kalfa, V.C.; Ackermann, M.R.; Palmquist, D.E.; McCray, P.B., Jr.; Tack, B.F. The ovine cathelicidin SMAP29 kills ovine respiratory pathogens in vitro and in an ovine model of pulmonary infection. Antimicrob. Agents Chemother. 2001, 45, 331-334.

39. Repp, K.K.; Menor, S.A.; Pettit, R.K. Microplate Alamar blue assay for susceptibility testing of Candida albicans biofilms. Med. Mycol. 2007, 45, 603-607.

40. Borgwardt, D.S.; Martin, A.; van Hemert, J.R.; Yang, J.; Fischer, C.L.; Recker, E.N.; Nair, P.R.; Vidva, R.; Chandrashekaraiah, S.; Progulske-Fox, A.; et al. Histatin 5 binds to Porphyromonas gingivalis hemagglutinin B (HagB) and alters HagB-induced chemokine responses. Sci. Rep. 2014, doi:10.1038/srep03904.

41. Yang, J.; Roy, A.; Zhang, Y. Protein-ligand binding site recognition using complementary binding-specific substructure comparison and sequence profile alignment. Bioinformatics 2013, 29, 2588-2595.

42. Yang, J.; Roy, A.; Zhang, Y. BioLiP: A semi-manually curated database for biologically relevant ligand-protein interactions. Nucleic Acids Res. 2013, 41, D1096-D1103.

(C) 2014 by the authors; licensee MDPI, Basel, Switzerland. This article is an open access article distributed under the terms and conditions of the Creative Commons Attribution license (http://creativecommons.org/licenses/by/4.0/). 